\title{
Clinical presentation of exclusive cystic fibrosis lung disease
} Inez Bronsveld, Jan Bijman, Frauke Mekus, Manfred Ballmann, Henk J Veeze,
Burkhard Tümmler

\begin{abstract}
The diagnosis of cystic fibrosis (CF) is based on the occurrence of two mutations in the cystic fibrosis transmembrane conductance regulator (CFTR) gene and on assays that measure the basic defect of abnormal chloride transport in the affected organs. However, in cases of atypical CF not all diagnostic tests may be positive. We present a patient with an atypical CF phenotype in whom the only presenting symptom was severe CF-like lung disease substantiated by an abnormal nasal potential difference. Genetic analysis showed that the patient was a symptomatic heterozygote, which suggests that one lesion in the CFTR gene may be sufficient to cause CF-like lung disease.

(Thorax 1999;54:278-281)
\end{abstract}

Keywords: cystic fibrosis; atypical cystic fibrosis; nasal potential difference; genetics

Departments of

Paediatrics and Cell

Biology, Erasmus

University Rotterdam,

Rotterdam,

The Netherlands

J Bijman

I Bronsveld

Department of Neonatology, Sophia Children's Hospital,

Rotterdam,

The Netherlands

$\mathrm{H} J$ Veeze

Department of Paediatrics and the Clinical CF Research Group, Medizinische

Hochschule Hannover,

D-30623 Hannover,

Germany

M Ballmann

F Mekus

B Tümmler

Correspondence to: Dr I Bronsveld.

Received 6 April 1998 Returned to author 23 July 1998

Revised manuscript received

9 October 1998

Accepted for publication

12 October 1998

\section{Patient history}

The 34 year old patient was the third child of Caucasian first generation cousins. The first child was born preterm with meconium ileus and died at day 10 . The second child died during infancy at six months and CF was suspected at necropsy. Our patient suffered from chronic nasal polyposis which had led to 13 polypectomies between the age of five and 23 years. By the age of 15 years she was referred to a chest physician because of shortness of breath during sports activity. Clubbing, subnormal lung function, and decreased exercise tolerance were noted. The diagnosis of CF was proposed because of the typical pulmonary manifestations but was discarded when normal sweat electrolyte concentrations were found. The differential diagnosis of allergy as the underlying disease was excluded by normal IgE skin prick tests and normal serum levels of specific IgE. Immotile cilia syndrome was excluded by the normal microscopic appearance of biopsy specimens of nasal cilia. Since adolescence she had been underweight (below 3rd percentile) and had recurrent lower airway infections. Over the years increased sputum production and chronic cough became a clinical problem. A lung biopsy specimen in 1984 showed a histological pattern consistent with $\mathrm{CF}$ (bronchiectasis with localised purulent bronchitis and surrounding fibrosis). Cultures of throat swabs or sputum were often positive for Staphylococcus aureus ( $>90 \%$ of samples) but never for Pseudomonas aeruginosa. However, the specific anti-P aeruginosa oprF IgG titre was positive, indicating that she had been exposed to $P$ aeruginosa. Bronchodilators and intermittent antibiotics were prescribed but the patient generally discontinued medication after a few days, even during acute respiratory tract infections. At the age of 23 her lung function was reduced (vital capacity 1.51 (48\% predicted)), her chest radiograph had a ChrispinNorman score of 20, grade 3 (range 0-38), her height was at the 25 th percentile and weight below the 3rd percentile. However, her pancreatic function was sufficient as shown by normal chymotrypsin levels in 1986, 1992, 1995, normal stool elastase levels $(386 \mathrm{mg} / \mathrm{g}$ ) in 1995 , and by ultrasound investigation of the pancreas. She had never received pancreatic enzymes or vitamin supplements. Serum levels of vitamins (vitamin A $370 \mu \mathrm{g} / \mathrm{l}$, vitamin $\mathrm{E}$ $11 \mathrm{mg} / \mathrm{l})$, bilirubin and liver enzymes were always in the normal range. Moreover, in 


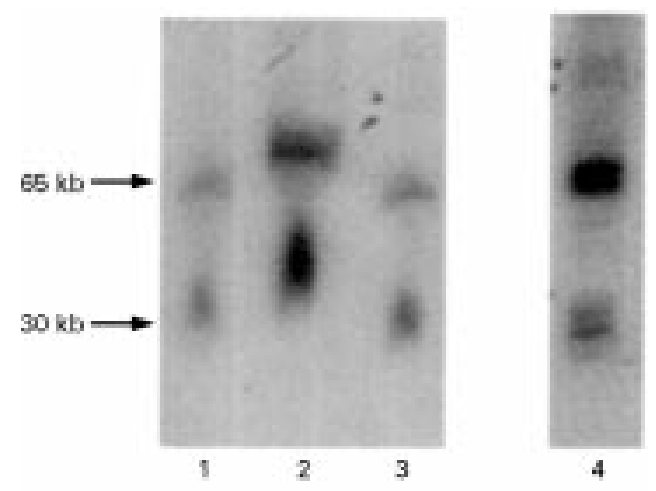

Figure 1 Autoradiogram of genomic ApaI digestions probed with CFTR cDNA (exon 7-24). No anomalous band pattern is seen for the sample from the patient (lane 1). For comparison, lane 4 shows the probe reactive fragments from a specimen which carries a deletion in one CFTR allele. ApaI cleaved fragments were separated in a $C H E F-D R^{\text {TMII }}$ cell at $5.6 \mathrm{~V} / \mathrm{cm}$ in $1 \%$ agarose gels $(0.5$ TBE buffer, $\left.10^{\circ} \mathrm{C}\right)$. Pulse times were linearly increased in two ramps from 5 to $20 \mathrm{~s}$ in 18 hours and from 5 to $90 \mathrm{~s}$ in 20 hours.

repetitive pilocarpine iontophoresis sweat tests performed since she was 11 years old the sweat electrolyte levels were always normal (range $7-32 \mathrm{mEq} / \mathrm{l}$.

\section{Methods}

This study was approved by the medical ethical committees of the Dutch and German participating hospitals and informed consent was obtained from the patient. All chemicals were obtained from the Sigma Chemical Co, St Louis, Missouri, USA.

\section{ANALYSIS OF THE CFTR GENE}

The promoter ( -3.8 to $-0.3 \mathrm{~kb}$ ) and coding regions and the exon flanking intron sequences of the CFTR gene were screened for mutations by single strand conformation polymorphism (SSCP) analysis ${ }^{112}$ and, in the case of the appearance of non-wild type band patterns in the high resolution SSCP gel, by subsequent sequencing. ${ }^{13}$ Deletions in the CFTR gene were sought by repeated Southern hybridisations of macrorestriction blots with CFTR cDNA probes encoding exon 1, exons 7-24, or the second nucleotide binding fold (codons 12021422). Preparation of unsheared genomic DNA from fresh blood, complete restriction digestions with ApaI, EagI, FspI, SalI or XhoI, pulsed field

Table 1 Electrophysiological results for the study patient. Mean (SD) values for a control group and a group of patients with CF are given for comparison

\begin{tabular}{llll}
\hline & $\begin{array}{l}\text { Control } \\
\text { group }\end{array}$ & $\begin{array}{l}\text { Study } \\
\text { patient }\end{array}$ & CF group \\
\hline $\begin{array}{l}\text { Nasal potential difference }(\mathrm{mV}) \\
\text { baseline and } \Delta \mathrm{PD} \text { after addition of: }\end{array}$ & $\mathrm{n}=25$ & & $\mathrm{n}=23$ \\
$\quad$ baseline & $-24(11)$ & -52 & $-45(10)$ \\
$\quad$ amiloride & $+10(6)$ & +21 & $+21(9)$ \\
$\quad \begin{array}{l}\mathrm{Cl}^{-} \text {free solution } \\
\text { isoprenaline }\end{array}$ & $-15(10)$ & -3 & $-1(5)$ \\
$\quad$ ATP & $-8(4)$ & -4 & $-2(3)$ \\
$\begin{array}{l}\text { Intestinal current measurement }\left(\mu \mathrm{A} / \mathrm{cm}^{2}\right) \\
\quad-1(3)\end{array}$ & 0 & $-1(3)$ \\
$\quad \mathrm{I}$ ac after addition of: & $\mathrm{n}=50$ & & $\mathrm{n}=51$ \\
$\quad$ carbachol & $-8.7(11)$ & -4.9 & $-8.7(11)$ \\
$\quad$ histamine (after DIDS incubation) & $38.5(23)$ & 45.5 & $-5.3(10)$ \\
& $33.0(26)$ & 19.4 & $-5.0(10)$ \\
\hline
\end{tabular}

gel electrophoresis, blotting and hybridisation followed protocols 1, 5, 7, 8 and 9 of Bautsch et $a l^{14}$ The intragenic CFTR haplotype was determined for the sequence alterations T854T and $\mathrm{M} 470 \mathrm{~V},{ }^{15}{ }^{16}$ the splice site polymorphism in intron 8 (TG) $)_{m} T_{n},{ }^{11}$ and the microsatellites IVS8CA, IVS17bCA, IVS17bTA. ${ }^{18}$

NASAL POTENTIAL DIFFERENCE (NPD)

NPD was measured using an adaptation of the method described previously. ${ }^{5}$ In short, the nasal turbinate was superfused $(1.7 \mathrm{ml} / \mathrm{min})$ for periods of three minutes with the following solutions (mol/l): saline to measure baseline PD; amiloride $\left(10^{-4}\right)$ to block $\mathrm{Na}^{+}$channels; gluconate with amiloride to assess spontaneous $\mathrm{Cl}^{-}$conductance; isoprenaline $\left(10^{-4}\right)$ in gluconate with amiloride to evaluate the presence of CFTR, and ATP $\left(10^{-3}\right)$ in isoprenaline/gluconate+amiloride solution to open non-CFTR $\mathrm{Cl}^{-}$channels. To access the submucosal space a small needle (25 gauge) was inserted into the forearm and filled with saline. Both the needle and superfusion catheter were connected to a high input resistance voltage measuring device via salt bridges and $\mathrm{Ag} / \mathrm{AgCl}$ electrodes. The saline solution consisted of (mmol/l): $\mathrm{NaCl}(120), \mathrm{Na}$ gluconate (25), $\mathrm{K}$ gluconate (5), $\mathrm{NaH}_{2} \mathrm{PO}_{4}$ (0.4), $\mathrm{Na}_{2} \mathrm{HPO}_{4}$ (2.4). In the gluconate solution $\mathrm{NaCl}$ was replaced by $\mathrm{Na}$ gluconate (145). All solutions were adjusted to $\mathrm{pH}$ 7.4.

INTESTINAL CURRENT MEASUREMENT (ICM)

The method used to study ICM has been described previously. ${ }^{4}$ Freshly obtained rectal biopsy specimens were mounted in saline solution in the Ussing chamber (aperture $1.2 \mathrm{~mm}$ ). After stabilising the basal short circuit current $\left(I_{\mathrm{sc}}\right)$ the tissue was exposed to the following inhibitors and secretagogues (mol/l) to the mucosal (M) or serosal (S) side: glucose $\left(10^{-2}\right.$, $\mathrm{M}+\mathrm{S})$; amiloride $\left(10^{-4}, \mathrm{M}\right)$; indomethacin $\left(10^{-5}, \mathrm{M}+\mathrm{S}\right)$ to inhibit basal $\mathrm{Cl}^{-}$secretion by inhibiting the endogenous prostaglandin formation; carbachol $\left(10^{-4}, \mathrm{~S}\right)$, a $\mathrm{Ca}^{2+}$ linked secretagogue; forskolin $\left(10^{-5}, \mathrm{M}+\mathrm{S}\right)+8$-bromo cyclic adenosine monophosphate (cAMP, $10^{-3}$, $\mathrm{M}+\mathrm{S}$ ) to open $\mathrm{Cl}^{-}$channels by activation of a cAMP-dependent protein kinase and phosphorylation of specific membrane proteins; 4,4'diisothiocyanatostilbene-2,2'-disulphonic acid (DIDS, $\left.2.10^{-4}, \mathrm{M}\right)$ to inhibit $\mathrm{Ca}^{2+}$ dependent $\mathrm{Cl}^{-}$secretion; and histamine $\left(5.10^{-4}, \mathrm{~S}\right)$ to reactivate the $\mathrm{Ca}^{2+}$ activated pathway.

\section{Results}

\section{CFTR GENETICS}

Despite the familial consanguinity, the patient was heterozygous at the CFTR locus which is shown by the different number of (TA $)_{n}$ repeats ( $\mathrm{n}=30,34)$ for the microsatellite at the locus IVS17bTA and her heterozygosity for a rare CFTR mutation. She was homozygous (TG) ${ }_{12} \mathrm{~T}_{7}-2-1$ for the CFTR haplotype (TG) ${ }_{m} T_{n}-M 470 V-T 854 T$. The combination of the $\mathrm{TG}_{12}$ repeat with the $\mathrm{T}_{7}$ allele and the $\mathrm{V} 470$ CFTR isoform are known to decrease significantly the amount and chloride channel activity of CFTR.$^{16}$ After all CFTR exons and flanking intron sequences and most of the promoter 


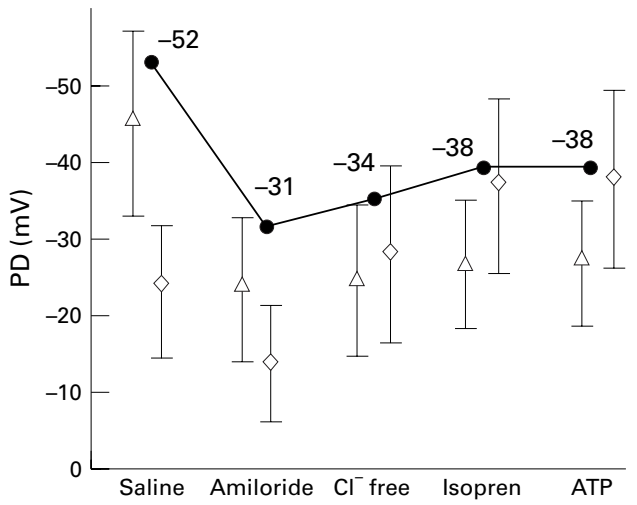

Figure 2 Nasal potential difference (PD) measurements of the patient $(\bullet)$ and mean (SD) PD values of 25 controls $(\diamond)$ and 23 patients with $C F$ (4) following superfusion with saline solution, amiloride $\left(10^{-4} \mathrm{M}\right)$ in saline solution, Cl free solution with amiloride, isoprenaline $\left(10^{-4} \mathrm{M}\right)$ in Cl free solution with amiloride, and $A T P\left(10^{-3} \mathrm{M}\right)$ in $\mathrm{Cl}$ free solution with amiloride and isoprenaline.

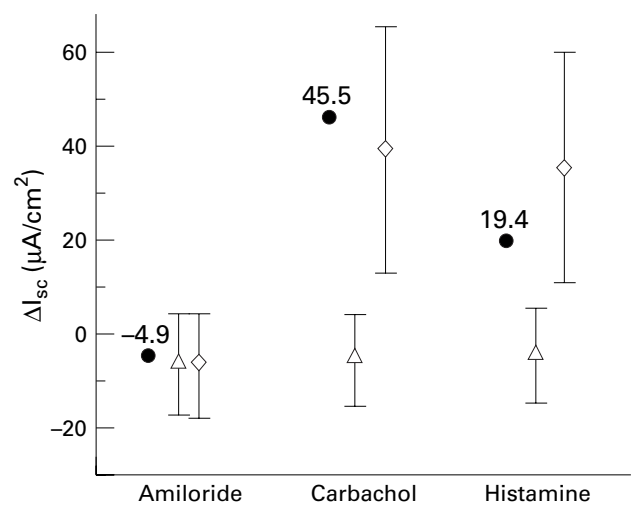

Figure 3 Measurements of intestinal current expressed as changes in short circuit current $\left(I_{s}\right)$ of the patient $(\bullet)$ and mean (SD) $I_{s c}$ of 50 controls $(\diamond)$ and 51 patients with $C F$ (4) following the addition of amiloride, carbachol, and exposure to 4,4'-diisothiocyanatostilbene-2,2'-disulphonic acid (DIDS) + histamine.

area up to $-4 \mathrm{~kb}$ had been screened by SSCP, one molecular lesion (the splice site consensus transition $1898+3 \mathrm{~A}->\mathrm{G}$ ) was identified. A pancreatic insufficient child with $\mathrm{CF}$ at our clinic is homozygous for this condition and exhibited the typical pulmonary and gastrointestinal manifestations of $\mathrm{CF}$ indicating that $1898+3 \mathrm{~A}->\mathrm{G}$ is a CF-causing lesion. No anomalous bands were seen in autoradiograms of macrorestriction blots probed with CFTR cDNAs, indicating that the two CFTR alleles of our patient do not carry any major genomic alteration (fig 1).

\section{DIAGNOSTIC ASSESSMENT}

On the day of electrophysiological investigation at the age of 32 she was underweight (below the 3rd percentile with a body mass index of $17 \mathrm{~kg} / \mathrm{m}^{2}$ ) and her lung function was severely reduced $\left(\mathrm{FEV}_{1} 0.391\right.$ (14\% predicted), FVC 1.231 (38\% predicted)). At this time she was treated with continuous oxygen and showed severe clubbing. Electrophysiological measurements were carried out by assessing the presence of chloride conductance in her airway and intestinal epithelium (table 1). The basal $\mathrm{NPD}$ was $-52 \mathrm{mV}$ (fig 2). In the presence of amiloride the PD depolarised to $-31 \mathrm{mV}$, a decrease of $40 \%$. Superfusion of gluconate in the presence of amiloride resulted in a net response of $-3 \mathrm{mV}$, indicating subnormal $\mathrm{Cl}^{-}$ conductance. With isoprenaline, which opens CFTR $\mathrm{Cl}^{-}$channels, only a small response of $-4 \mathrm{mV}$ was obtained which suggested that few CFTR channels are present. No ATP response, which is usually indicative of the presence of alternative $\mathrm{Cl}^{-}$channels, ${ }^{20}$ was seen in the airway tissue.

In previous ICM studies carbachol has provoked a negative reversed $I_{\mathrm{sc}}$ in rectal tissue of patients with $\mathrm{CF}$, sometimes followed by a positive residual response indicating the presence of residual $\mathrm{Cl}^{-}$secretion. In our patient the ICM showed a $\mathrm{Cl}^{-}$secretory current in the normal range on addition of carbachol (fig 3). DIDS, which inhibits the alternative pathway of $\mathrm{Ca}^{2+}$ activated $\mathrm{Cl}^{-}$currents, did not influence the $\mathrm{Cl}^{-}$current, suggesting the presence of normal CFTR mediated chloride conductance in the intestine.

\section{Discussion}

The clinical and diagnostic features presented by this case are conflicting in terms of the expression of the basic defect in different tissues. In typical CF defective electrolyte transport in the sweat gland, intestinal and airway epithelium is shown by a pathological outcome of the sweat test, ICM and NPD. In our case, however, the sweat chloride concentration and ion flow in the intestine were normal while the NPD values were abnormally high. Pathologically raised NPD values have so far only been found in CF and not in any other lung disease with related clinical manifestations such as $\alpha_{1}$-antitrypsin deficiency, immotile cilia syndrome, or congenital bronchiectasis. ${ }^{21}$ As well as a high baseline nasal PD, the patient's gluconate and isoprenaline response were also in the $\mathrm{CF}$ range. However, they do point to the presence of little residual CFTR $\mathrm{Cl}^{-}$permeability in her respiratory epithelium. The clinical symptoms of our patient, such as progressive obstructive bronchitis and bronchiectasis, sputum production, and pathological bacterial flora, are typical of $\mathrm{CF}$ and she has been permanently on oxygen since the age of 30 . This could explain her anorexic status since there is no sign of malabsorption or gastrointestinal disease, as confirmed by normal vitamin $A$ and E levels, pancreatic sufficiency, and a normal ICM. This highly discordant expression of the basic defect in different tissues is described here for the first time: CFTR function was unaffected in gastrointestinal tissue whereas in airway tissue the abnormally low $\mathrm{Cl}^{-}$conductance can only be accounted for by defective epithelial $\mathrm{Cl}^{-}$transport. Other cases of $\mathrm{CF}$ with normal sweat test results and pulmonary disease, as described for patients carrying the A455E or $3849+10 \mathrm{~kb} \mathrm{C}->\mathrm{T}$ mutation, ${ }^{7822} 23$ can clearly be diagnosed by an abnormal ICM even when there are few or no clinical signs of gastrointestinal involvement. ${ }^{10}$

The CFTR gene was screened for disease causing lesions in all exons and flanking intron sequences and on one chromosome a sequence alteration in a donor splice site was found 
$(1898+3 \mathrm{~A}->\mathrm{G})$. This sequence alteration was first described in a compound heterozygous pancreatic sufficient patient (Ferrari et al, personal communication) and was found also in a pancreatic insufficient CF patient homozygous for this condition (see above). According to CFTR mutation analysis and the family anamnesis, our patient is a carrier for one CFTR mutation and hence should not express any $\mathrm{CF}$ symptoms. However, she carries an unfavourable combination of common intragenic polymorphisms. She is homozygous $\mathrm{TG}_{12} \mathrm{~T}_{7}$ for the $\mathrm{TG}_{\mathrm{m}} \mathrm{T}_{\mathrm{n}}$ polymorphism at the intron 8 splice acceptor site, and the $\mathrm{TG}_{12}$ repeat together with the $\mathrm{T}_{7}$ stretch places the branch point nucleotide in an unfavourable position for splicing leading to $30 \%$ of exon $9^{-}$CFTR transcript which are known to be translated in CFTR proteins that do not mature. ${ }^{1624}$ Moreover, she is homozygous for the V470 allele in exon 10 . V470 CFTR proteins have a 1.7 fold decreased intrinsic chloride channel activity compared with M470 CFTR proteins. ${ }^{16}$ These predisposing polymorphisms in the intragenic background decrease the expression and function of CFTR. Yet, they are present in both rectal and nasal tissue and cannot account for the unimpaired function of CFTR in the intestine while in the nasal tissue almost complete absence of $\mathrm{Cl}^{-}$conductance was found. However, the patient's consanguineous descent leads to a genome-wide overrepresentation of homozygous genotypes which may lead to further unfavourable combinations of factors that modify CFTR expression or lung function. As gastrointestinal disease is not present, we propose that the genetic background predisposes to severe lung disease caused by tissue specific regulatory elements which lead to the loss of CFTR function exclusively in the respiratory epithelium.

This work was supported by the Deutsche Forschungsgemeinschaft.

1 Welsh MJ, Tsui LC, Boat TF, et al. Cystic fibrosis. In: Scriver CR, Beaudet AL, Sly WS, Valle D, eds. The metabolic and molecular basis of inherited disease. New York: McGraw Hill, 1995: 3799-876.

2 Bear $\mathrm{CE}, \mathrm{Li} \mathrm{CH}$, Kartner $\mathrm{N}$, et al. Purification and functional reconstitution of the cystic fibrosis transmembrane conductance regulator (CFTR). Cell 1992;68:80918.

3 Gibson LE, Cooke RE. A test for concentration of electrolytes in sweat in cystic fibrosis of the pancreas utilizing pilocarpine by iontophoresis. Pediatrics 1959;23:545-9.
in 4 Veeze $\mathrm{HJ}$, Sinaasappel M, Bijman J, et al. Ion transport abnormalities in rectal suction biopsies from children

5 Knowles MR, Carson JL, Collier AM, et al. Measurements of nasal transepithelial electrical potential differences in normal human subjects in vivo. Am Rev Respir Dis 1981;124:484-90.

6 Knowles MR, Paradiso AM, Boucher RC. In vivo nasal potential difference: techniques and protocols for assessing efficacy of gene transfer in cystic fibrosis. Hum Gene Ther 1995;6:445-55.

7 Gan KH, Veeze HJ, van den Ouweland AM, et al. A cystic fibrosis mutation associated with mild lung disease. $\mathrm{NEngl}$ f Med 1995;333:95-9.

8 Gilbert F, Li Z, Arzimanoglou I, et al. Clinical spectrum in homozygotes and compound heterozygotes inheriting cystic fibrosis mutation $3849+10 \mathrm{~kb} \mathrm{C}>\mathrm{T}$ : significance for geneticists. Am ₹ Med Genet 1995;58:356-9.

9 Kerem E, Rave-Harel N, Augarten A, et al. A cystic fibrosis transmembrane conductance regulator splice variant with
partial penetrance associated with variable cystic fibrosis presentations. Am f Respir Crit Care Med 1997;155:191420 .

10 Veeze HJ, Halley DJ, Bijman J, et al. Determinants of mild clinical symptoms in cystic fibrosis patients. $\mathcal{F}$ Clin Invest 1994;93:461-6

11 Dörk T, Mekus F, Schmidt K, et al. More than 50 different CFTR mutations in a large group of German cystic fibrosis patients. Hum Genet 1994;94:533-42.

12 Ravnik-Glavcak M, Glavcak D, Dean M. Sensitivity of single strand conformation polymorphism and heteroduplex method $801-7$.

13 Zielenski J, Rozmahel R, Bozon D, et al. Genomic sequence of the CFTR gene. Genomics 1991;10:214-28.

14 Bautsch W, Römling U, Schmidt KD, et al. Long-range restriction mapping of genomic DNA. In: Dear PH, ed. Genome mapping - a practical approach. Oxford: Oxford University Press, 1997: 281-313.

15 Dörk T, Neumann T, Wulbrand U, et al. Intra- and extragenic marker haplotypes of CFTR mutations in cystic fibrosis families. Hum Genet 1992;88:417-25.

16 Cuppens H, Lin W, Jaspers M, et al. Polyvariant mutant cystic fibrosis transmembrane conductance regulator genes. F Clin Invest 1998;101:487-96.

17 Teng $\mathrm{H}$, Jorissen $\mathrm{M}$, van Poppel $\mathrm{H}$, et al. Increased proportion of exon 9 alternatively spliced CFTR transcript in vas deferens compared with nasal epithelial cells. Hum Mol Genet 1997;6:85-90.

18 Morral N, Estivill X. Multiplex amplification of three microsatellites within the CFTR gene. Genomics 1992;13: 1362-4.

19 Mekus F, Dörk T, Deufel T, et al. Analysis of microsatellites by direct blotting electrophoresis and chemiluminescence detection. Electrophoresis 1995:16:1886-8.

20 Knowles MR, Clarke LL, Boucher RC. Activation by extracellular nucleotides of chloride secretion in the airway epithelia of patients with cystic fibrosis. $N$ Engl $\mathcal{f} \mathrm{Med}$ 1991;325:533-8.

21 Knowles MR, Gatzy J, Boucher RC. Increased bioelectrical potential difference across respiratory epithelia in cystic fibrosis. N Engl f Med 1981;305:1489-95.

22 Dreyfus DH, Bethel R, Gelfand EW. Cystic fibrosis $3849+10 \mathrm{~kb} C>$ T mutation associated with severe pulmo$3849+10 \mathrm{~kb} C \mathrm{C}$ mutation associated with severe pulmo-
nary disease and male fertility. Am $\mathcal{F}$ Respir Crit Care Med 1996;153:858-60.

23 Highsmith WE, Burch LH, Zhou Z, et al. A novel mutation in the cystic fibrosis gene in patients with pulmonary disease but normal sweat chloride concentrations. $N$ Engl f Med 1994;331:974-80.

24 Strong TV, Wilkinson DJ, Mansoura MK, et al. Expression of an abundant alternatively spliced form of the cystic fibrosis transmembrane conductance regulator (CFTR) gene is not associated with a cAMP-activated chloride conductance. Hum Mol Genet 1993;2:225-30. 